\title{
Valorization of okara oil for the encapsulation of Lactobacillus plantarum
}

\author{
G. Quintana, E. Gerbino, A. Gómez-Zavaglia* \\ Center for Research and Development in Food Cryotechnology (CCT-Conicet La Plata, UNLP) RA-1900, Argentina
}

\section{A R T I C L E I N F O}

\section{Keywords:}

Lactic acid bacteria

Oil-in-water emulsions

Spray-drying

Freeze-drying

Stability

\begin{abstract}
A B S T R A C T
Oil-in-water $(\mathrm{O} / \mathrm{W})$ emulsions of okara oil-caseinate $(1: 2 ; 1: 3$ and $1: 4 \mathrm{O} / \mathrm{W}$ ratios) were used to encapsulate Lactobacillus plantarum CIDCA 83114. Once encapsulated, microorganisms were freeze-dried or spray-dried, and observed by scanning electronic and confocal microscopies. A physical characterization of the dehydrated capsules was carried out by determining their moisture content, water activity, particle size, polydispersity index and zeta potential. Determining the induction times and peroxide values provided information about their susceptibility to oxidation. In turn, bacterial stability was analyzed by plate counting before and after freezedrying and spray-drying, and during storage at $4{ }^{\circ} \mathrm{C}$.

Spray-dried emulsions had lower $Z$-sizes and polydispersity indexes, higher induction times and lower peroxide values than the freeze-dried ones, thus resulting better systems to protect L. plantarum CIDCA 83114. In addition, the culturability of spray-dried bacteria did not decrease neither after spray-drying nor up to 60 days of storage at $4{ }^{\circ} \mathrm{C}$.

The results showed that the better physical-chemical stability of spray-dried capsules determined the greater stability of microorganisms. This demonstrates the importance of defining adequate emulsions' formulations for an efficient encapsulation of microorganisms, with promising applications in the development of novel functional foods.
\end{abstract}

\section{Introduction}

Okara is the by-product remaining from the soy milk production, after filtration of the smashed soybeans seeds (Stanojevic, Barac, Pesic, Jankovic, \& Vucelic-Radovic, 2013). It is obtained in large quantities (about $1.1 \mathrm{~kg}$ per kilogram of soybean processed for soymilk production), thus posing an important disposal problem (Li et al., 2012). To avoid such problem, great efforts have been employed to use okara for the formulation of different products (Vong \& Liu, 2016).

Dehydrated okara contains about $9-10 \%$ humidity, $21 \%$ proteins, $55 \%$ whole fiber, $1.5 \%$ ash and $13-14 \%$ fats and oils (Quintana, Gerbino, \& Gomez-Zavaglia, 2017). Because of the nutritional value of its components (proteins of high nutritional value, dietary fiber, antioxidants, unsaturated lipids), okara appears as a valuable source of different ingredients for the formulation of functional foods (Vong \& Liu, 2016). Defatted okara can be used as primary ingredient for the formulation of dry breakfast cereals or as meat extender (Shurtleff \& Aoyagi, 2000). Okara oil has potential applications in cosmetic, pharmaceutical and food industry. In this regard, using super-critical $\mathrm{CO}_{2}$ enables the recovery of nutritionally valuable compounds from okara oil, namely polyunsaturated fatty acids, phytosterols and phenolic compounds, such as soy isoflavones, genistein and daidzein (Borhan, Gani, \& Shamsuddin, 2014; Quitain, Oro, Shunsaku, \& Moriyoshi, 2006). This represents an added value in preventing chronic diseases (FAO, 2010) and opens opportunities for the development of novel applications aiming at using this by-product.

Lactic acid bacteria have an important role in the food and pharmaceutical industries, as they are extensively used as starters in the development of food and probiotic products. However, the decrease of water activity occurring during preservation and technological processes is often detrimental, leading to damages on the cellular structures or death (Santos, Gerbino, Araujo-Andrade, Tymczyszyn, \& Gomez-Zavaglia, 2014; Tymczyszyn et al., 2008). To prevent these problems, bacterial microencapsulation into polymer matrices appears as an adequate strategy to ensure mechanical integrity during production processes (exposure to high/low temperatures, oxidation, shear, etc.), desiccation and storage (packaging and environment conditions, including moisture, oxygen, temperature, etc.) (Chávarri, Marañón, \& Villarán, 2012). Encapsulation shell agents include a variety of polymers, carbohydrates, fats and waxes, depending on the material to be

Abbreviations: $\zeta$ potential, zeta potential; Đ, polydispersity index; MRS, de Man, Rogosa, Sharpe broth; CFU, colony forming units; PBS, phosphate buffer saline; O/W, oil-in-water; ds, dried sample; $\mathrm{a}_{\mathrm{w}}$, water activity; ANOVA, Analysis of variance

* Corresponding author at: Calle 47 y 116 La Plata, Buenos Aires 1900, Argentina.

E-mail address: angoza@qui.uc.pt (A. Gómez-Zavaglia). 


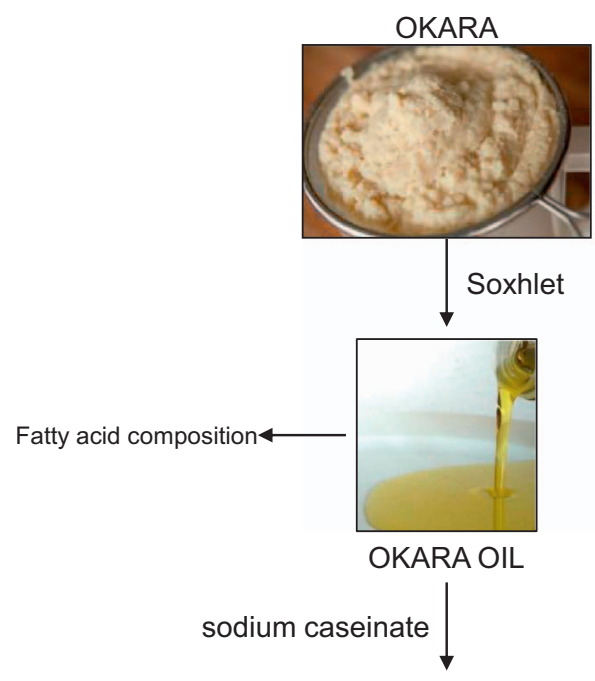

Emulsion (control)

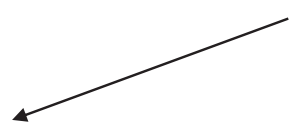

Freeze-drying
Scheme 1. Experimental sequence of experiments.

microscopic observations (SEM, confocal)
moisture content
wáter activity
Z-size, polydispersity index, zeta potential
induction time
peroxide determination
plate counts (after dehydration and during storage)

protected. The coating of sealed capsules must be semipermeable and mechanically resistant to the adverse conditions above mentioned (Chávarri et al., 2012).

Microorganisms are usually suspended in a given encapsulating agent, forming emulsions or suspensions. Such emulsions are then dehydrated, generally by freeze-drying or spray-drying (Petrovic, Nedovic, Dimitrijevic-Brankovic, Bugarski, \& Lacroix, 2007). Entrapment of probiotic bacteria in emulsion droplets has been suggested to stabilize different species of lactic acid bacteria (Hou, Lin, Wang, \& Tzen, 2003; Pimentel-González, Campos-Montiel, Lobato-Calleros, Pedroza-Islas, \& Vernon-Carter, 2009; Rodríguez-Huezo et al., 2014; Zhang, Lin, \& Zhong, 2015). In this regard, Hou et al. (2003) succeeded at increasing about $10^{4}$ times the intestinal survival rate of Lactobacillus delbrueckii ssp. bulgaricus by entrapping microorganisms in the droplets of reconstituted sesame oil body emulsions. Pimentel-González et al. (2009) successfully encapsulated Lactobacillus rhamnosus using waterin-oil-in-water emulsions prepared with canola oil and sweet whey (Pimentel-González et al., 2009). Milk fat was also used for encapsulation of lactic acid bacteria. In addition, preparing emulsion droplets with multiple lipid-protein-pectin layers provides additional protection for Lactobacillus salivarius strains (Zhang et al., 2015). Canola oil was also used to encapsulate Lactobacillus plantarum in double emulsions containing aguamiel or sweet whey as inner aqueous phases, and the obtained emulsions were successfully incorporated during cheese manufacture (Rodríguez-Huezo et al., 2014). The presence of whey proteins, inulins or fructo-oligosaccharides are reported to play an important role in the protection of the encapsulated microorganisms. Although emulsification technologies have demonstrated a great efficiency for the encapsulation of probiotics, there is still a long way to undergo in the development of more efficient entrapment systems. In this sense, when analyzing the recovery of entrapped bacteria, the focus has been always put on the composition of the aqueous components of emulsions. In fact, for improving bacterial recovery, different aqueous components have been assayed to formulate emulsions (Hou et al., 2003; Pimentel-González et al., 2009; Rodríguez-Huezo et al., 2014; Zhang et al., 2015). However, little attention has been paid to the oil components. This aspect is especially important because the chemical and physical properties of such oils determine their ability to form small droplets, leading to stable emulsions after homogenization (Bai \& McClements, 2016). Lipid oxidation is another factor defining the stability of the emulsions, as it usually limits the shelf-life of fat containing products (Jacobsen, 2010). For this reason, an adequate selection of oils is very important to prevent oxidation during storage, thus contributing for the long term stability of encapsulated microorganisms.

The aim of this work was to formulate different okara oil-caseinate emulsions and use them to encapsulate L. plantarum CIDCA 83114, a strain with demonstrated inhibitory properties against $E$. coli O157:H7, Shigella and Salmonella [Hugo, Kakisu, De Antoni, \& Pérez, 2008; Golowczyc, Silva, Teixeira, De Antoni, \& Abraham, 2011; Kakisu, Abraham, Tironi Farinati, Ibarra, \& De Antoni, 2013; Kakisu, Bolla, Abraham, de Urraza, \& De Antoni, 2013]. The O/W emulsions were freeze-dried and spray-dried, and the obtained particles were characterized by determining their size, zeta-potential ( $\zeta$-potential) and polydispersity index $(Ð)$. The stability of oil to oxidation was assessed by determining the induction time and peroxide values. In turn, the bacterial stability was evaluated by plate counting before and immediately after encapsulation, and during 90 days of storage at $4{ }^{\circ} \mathrm{C}$. 


\section{Materials and methods}

\subsection{Materials}

Okara, obtained from Soyana S.H. (San Martín, Argentina); sulphuric acid, methanol, chloroform, acetone, butanol, isooctane and isopropanol (Merck, Darmstadt, Germany); sodium thiocyanate, ferrous chloride and cumene hydroperoxide (Sigma-Aldrich, St. Louis, MO, USA); $\mathrm{KH}_{2} \mathrm{PO}_{4}$ (J. T. Baker, Mexico); $\mathrm{NaCl}$ (Sigma-Aldrich, USA); $\mathrm{Na}_{2} \mathrm{HPO}_{4}$ (Anedra, Angentina); sodium caseinate (Sigma Chemical, St. Louis, MO, USA); MRS broth (Biokar Diagnostics, France); agar (Parafarm, Argentina); non-fat milk (Fisher Scientific, MA, USA); TOPRO-3 (Sigma-Aldrich, St. Louis, MO, USA); Nile red (Sigma-Aldrich, St. Louis, MO, USA).

\subsection{Methods}

The experimental sequence of experiments is shown in Scheme 1.

\subsubsection{Obtaining and characterization of okara oil}

After being received, okara was centrifuged 5 times to remove the excess of water. The sediment was frozen at $-80^{\circ} \mathrm{C}$ for $48 \mathrm{~h}$ and then, freeze-dried on a Heto FD4 equipment (Heto Lab Equipment, Denmark) for $48 \mathrm{~h}$ (temperature of condenser: $-50{ }^{\circ} \mathrm{C}$; chamber pressure: 0.04 mbar). The okara oil was extracted with diethyl ether solvent in a Soxhlet system (AOAC, 1995).

The fatty acid composition of the oil was analyzed according to IUPAC 2.302 standard method (IUPAC, 1992). The fatty acids methyl esters were prepared by adding $2 \mathrm{~mL}$ sulphuric acid $(20 \mathrm{~g} / \mathrm{L}$ in methanol) to $3 \mathrm{mg}$ oils, heating at $60^{\circ} \mathrm{C}$ for $2 \mathrm{~h}$, extracting the esters with $1 \mathrm{~mL}$ chloroform-water $(2: 0.7 \mathrm{v} / \mathrm{v})$ and washing twice with $0.7 \mathrm{~mL}$ water. The obtained fatty acids methyl esters were analyzed on a gas chromatograph interfaced with a mass spectrometer detector (Shimadzu QP 5050A, Tokyo, Japan) using capillary column ZB-5 $(30 \mathrm{~m} \times 0.25 \mathrm{~mm})$. The conditions of analysis were: injection temperature $250{ }^{\circ} \mathrm{C}$, detector temperature $280^{\circ} \mathrm{C}$ and column temperature initially $100{ }^{\circ} \mathrm{C}$ increased to $280{ }^{\circ} \mathrm{C}$ at $6{ }^{\circ} \mathrm{C} \mathrm{min}^{-1}$. The fatty acids methyl esters were identified by mass spectrometry. The fatty acid composition was determined by considering the relative contribution of each peak area with regard to the sum of the areas corresponding to all peaks. Results were expressed as $\%$ of the total area.

\subsubsection{Bacterial strain and growth conditions}

L. plantarum CIDCA 83114 was isolated from kefir grains (Garrote, Abraham, \& De Antoni, 2001) and maintained frozen at $-80{ }^{\circ} \mathrm{C}$ in $120 \mathrm{~g} / \mathrm{L}$ non-fat milk solids. The strain belongs to the CIDCA culture collection and was identified by molecular methods, as previously published (Garrote et al., 2001; Golowczyc et al., 2008).

Microorganisms were cultured twice in MRS broth (de Man, Rogosa, \& Sharpe, 1960) at $37^{\circ} \mathrm{C}$ in aerobic conditions. Cultures in the stationary phase $\left(\sim 1 \times 10^{13} \mathrm{CFU} / \mathrm{mL}\right)$ were harvested by centrifugation at $8000 \mathrm{rpm}$ for $10 \mathrm{~min}$, washed twice with phosphate saline buffer (PBS, $\mathrm{KH}_{2} \mathrm{PO}_{4} 0.144 \mathrm{~g} / \mathrm{L}, \mathrm{NaCl} 9 \mathrm{~g} / \mathrm{L}, \mathrm{Na}_{2} \mathrm{HPO}_{4} 0.795 \mathrm{~g} / \mathrm{L}, \mathrm{pH} 7.2$ ) and suspended in the same volume of $6 \% \mathrm{w} / \mathrm{v}$ sodium caseinate.

\subsubsection{Preparation of oil-in-water $(\mathrm{O} / \mathrm{W})$ emulsions}

Microencapsulation was performed using an oil-in-water (O/W) emulsion system containing different concentrations of okara oil (1.5, 2.0 , and $3.0 \% \mathrm{w} / \mathrm{v}$ ), and a constant concentration of sodium caseinate $(6 \% \mathrm{w} / \mathrm{v})$ (Dianawati, Mishra, \& Shah, 2016). This way the O/W ratios remained 1:4, 1:3 and 1:2, respectively. Okara oil and caseinate mixtures were then emulsified using an Ultra Turrax T25 high-shear probe mixer (IKA, Staufen im Breisgau, Germany) for $5 \mathrm{~min}$ at $13500 \mathrm{rpm}$ and $20^{\circ} \mathrm{C}$. O/W emulsions (1:4 ratio) in which no microorganisms were added to the aqueous phase were used as controls.

\subsubsection{Freeze-drying, spray-drying and storage}

$100 \mathrm{~mL}$ of $\mathrm{O} / \mathrm{W}$ emulsions containing bacteria in the stationary phase were frozen at $-80{ }^{\circ} \mathrm{C}$ for $12 \mathrm{~h}$, and freeze-dried in a Rificor L-AB4-C (Buenos Aires, Argentina), operating with the condenser at $-45{ }^{\circ} \mathrm{C}$ in a chamber pressure of 0.04 mbar. The freeze-drying process lasted for $48 \mathrm{~h}$. Non-encapsulated bacteria suspended in PBS, and 1:4 $\mathrm{O} / \mathrm{W}$ freeze-dried emulsions not containing microorganisms were used as controls.

In parallel assays, $500 \mathrm{~mL} \mathrm{O/W}$ emulsions containing microorganisms in the stationary phase were spray-dried in a laboratory-scale spray-dryer (Büchi B290 mini spray-dryer, Flawil, Switzerland) at a constant air inlet temperature of $145^{\circ} \mathrm{C}$ and an outlet temperature of $60{ }^{\circ} \mathrm{C}$. Controls: microorganisms grown in MRS broth harvested, neutralized and resuspended in PBS (non-encapsulated microorganisms) and spray-dried $\mathrm{O} / \mathrm{W}$ emulsions not containing microorganisms.

Before and after freeze-drying or spray-drying, microorganisms were serially diluted in PBS, plated on MRS agar and incubated at $37{ }^{\circ} \mathrm{C}$ in aerobic conditions for $48 \mathrm{~h}$. Plate counts were expressed as $\log \mathrm{CFU} /$ g.

Dehydrated bacteria (both freeze-dried and spray-dried) were stored for 90 days at $4{ }^{\circ} \mathrm{C}$ in silica gel containing recipients, and plate counted every 15 days. Plate counts were expressed as $\log \mathrm{N} / \mathrm{N}_{0}$ where $\mathrm{N}_{0}$ was the plate count a time 0 and $\mathrm{N}$, the plate count at each time of storage.

\subsubsection{Microscopic observations}

2.2.5.1. Scanning electronic microscopy. Dehydrated samples were frozen in liquid nitrogen and fractured using a cold scalpel blade, and examined with a FEI model Quanta 200 electron microscope (The Netherlands). Samples were mounted onto bronze stubs by using a double-sided tape and examined without any metal or carbon coating at low pressure and an acceleration voltage of $12.5 \mathrm{kV}$.

2.2.5.2. Confocal laser scanning microscopy analysis. Two dyes were used for confocal laser scanning microscopy: TO-PRO-3 and Nile red. Microorganisms were visualized using TO-PRO-3, which is an excellent far red-fluorescent nuclear and chromosome counterstain. The dye exhibits far-red fluorescence with excitation at $642 \mathrm{~nm}$ and emission at $661 \mathrm{~nm}$. In turn, Nile red was used to stain the O/W emulsions. A $0.01 \%$ $w / \mathrm{w}$ Nile red staining solution was prepared by dissolving $0.001 \mathrm{~g}$ of the dye in $10 \mathrm{~mL}$ of acetone. The solution was stored in the dark at $20{ }^{\circ} \mathrm{C}$. Nile red dye exhibits green fluorescence with excitation at $510-560 \mathrm{~nm}$ and emission at $590 \mathrm{~nm}$.

Freeze-dried and spray-dried emulsions were dispersed in $10 \mathrm{~mL}$ distilled deionized water under constant magnetic stirring to obtain a concentration of $\sim 10^{8}$ cells $/ \mathrm{mL}$. Then, $1 \% \mathrm{v} / \mathrm{v}$ of Nile red was added and samples were incubated for $1 \mathrm{~h}$ at $37^{\circ} \mathrm{C}$. Afterwards, an equal volume of $50 \% \mathrm{v} / \mathrm{v}$ methanol was incorporated and samples were incubated at $37^{\circ} \mathrm{C}$ for $5 \mathrm{~min}$. Finally $1 \mu \mathrm{L}$ of TO-PRO-3 (final concentration: $0.8 \mu \mathrm{M}$ ) was added and samples were incubated at $37^{\circ} \mathrm{C}$ for $5 \mathrm{~min}$. All samples were observed in a confocal laser-scanning microscope (Leica TCS SP5 Leica Microsystems, Wetzlar, Germany), using an excitation wavelength of $642 \mathrm{~nm}$. Emulsions were observed with no excitation wavelength.

\subsubsection{Characterization of dehydrated emulsions}

2.2.6.1. Moisture content. Moisture content of the freeze-dried and spray-dried samples were determined by measuring their weight loss upon drying in a vacuum oven at $70{ }^{\circ} \mathrm{C}$ until constant weight (AOAC, 1980). Dehydrated emulsions without microorganisms were used as controls. Moisture results were expressed as grams of water per $100 \mathrm{~g}$ of dried sample (ds).

2.2.6.2. Water activity $\left(a_{w}\right)$. The $\mathrm{a}_{\mathrm{w}}$ of freeze-dried and spray-dried samples was determined using an Aqualab water activity instrument (Aqualab, Model Series 3TE, USA). Capsules not containing bacteria were used as controls. The equipment was calibrated using standard salt 
solutions provided by the manufacturer.

2.2.6.3. Particle size, polydispersity index $(\nexists)$ and zeta potential ( $\zeta)$. All measurements were recorded at $37^{\circ} \mathrm{C}$ on freshly prepared emulsions as well as after freeze-drying and spray-drying, using a Malvern Instrument Zetasizer Nano-Z (Malvern Instruments, Malvern, UK). For all measurements, samples were dispersed in $0.15 \mathrm{M} \mathrm{NaCl}\left(\mathrm{pH} 7 ; 37^{\circ} \mathrm{C}\right.$, $30 \mathrm{~min}$ ) under constant magnetic stirring. They were then appropriately diluted to obtain about $10^{5}$ particles $/ \mathrm{mL}$ and vortexed for $30 \mathrm{~s}$ before determinations.

The average hydrodynamic particle size ( $Z$-average) and $Đ$ were determined by using dynamic light scattering at backward scattering $\left(173^{\circ}\right)$ with the Zetasizer 6.20 software. $\zeta$-potential was determined using a combination of measurement techniques: electrophoresis and laser Doppler velocimetry (Laser Doppler Electrophoresis). The $\zeta$-potential values were provided directly by the instrument. An average value of $\zeta$-potential was obtained from at least 20 determinations for each sample.

2.2.6.4. Induction time. The induction time, lag period during which oils show stability to oxidation, for both freeze-dried and spray-dried emulsions was determined according to AOAC Cd12-57, using a Rancimat 743 equipment (Metrohm AG, Herisau, Switzerland). Samples weighing $1 \mathrm{~g}$ were processed at $98^{\circ} \mathrm{C}$, with an air flux of $20 \mathrm{~L} / \mathrm{h}$. Dehydrated $\mathrm{O} / \mathrm{W}$ emulsions prepared in the absence of microorganisms were used as controls.

2.2.6.5. Peroxide determination. Lipid oxidation was evaluated by determining the peroxide value. The oil was extracted according to Partanen, Hakala, Sjövall, Kallio, and Forssell (2005). Briefly, $0.5 \mathrm{~g}$ of dehydrated samples containing microorganisms were suspended in $5 \mathrm{~mL}$ of distilled water and shaken until complete dissolution. $300 \mu \mathrm{L}$ of suspensions were taken and vortexed 3 times for $10 \mathrm{~s}$ with $1.5 \mathrm{~mL}$ of an isooctane/isopropanol $(3: 1 \mathrm{v} / \mathrm{v})$ mixture. The phases were separated. Peroxide values were determined on the upper phase according to McClements (1999). About $10-100 \mu \mathrm{L}$ of the extraction medium were added to $2.8 \mathrm{~mL}$ of methanol/butanol $(2: 1 \mathrm{v} / \mathrm{v}), 15 \mu \mathrm{L}$ of 3.94 M thiocyanate solution and $15 \mu \mathrm{L}$ of $0.072 \mathrm{M}$ acidic solution of ferrous iron. The samples were briefly vortexed, left $20 \mathrm{~min}$ in the dark, and the absorbance at $510 \mathrm{~nm}$ was read in a spectrophotometer (Shimadzu, Kyoto, Japan). Standard curves were carried out using cumene hydroperoxide. Capsules not containing microorganisms $(\mathrm{O} / \mathrm{W}$ : 1:4) were used as controls.

\subsubsection{Statistical analysis}

All the assays were conducted in triplicate and in three independent assays. Average values were used for data analysis. Analysis of variance (ANOVA) was carried out for all the assays, using the program GraphPad Prism 5 (GraphPad Software Inc., San Diego, CA, 2007). Analysis of variance (ANOVA) was carried out using the statistical program STATISTIX 8 Software (Analytical Software, Tallahassee, FL, USA). Means were compared by two-sided Dunett's multiple comparison test and the difference were considered significant when $p<0.05$.

\section{Results and discussion}

\subsection{Characterization of okara oil}

Okara constituents are valuable ingredients for the food and/or pharmaceutical industries. In this work, okara oil was used for the formulation of stable $\mathrm{O} / \mathrm{W}$ emulsions aiming at protecting L. plantarum CIDCA 83114 during both dehydration and storage. The efficiency of such encapsulation strategy requires an integrative analysis considering not only the bacterial culturability but also the oil stability.

Table 1 shows the fatty acid composition of okara oil. C18:2 (n-6)
Table 1

Fatty acid composition of okara oil (\% of total fatty acids) ${ }^{\mathrm{a}}$.

\begin{tabular}{ll}
\hline Fatty acid & Okara oil \\
\hline C16:0 & 11.57 \\
C16:1 & 0.08 \\
C18:0 & 4.43 \\
C18:1 $(n-9)$ & 20.04 \\
C18:1 $(n-7)$ & 1.30 \\
C18:2 $(n-6)$ & 54.61 \\
C18:3 $(n-3)$ & 7.97 \\
\hline
\end{tabular}

${ }^{\text {a }}$ Standard deviation below $1 \%$ in all cases.

and C18:1 ( $n-9)$ were the main fatty acids, accounting $74.65 \%$ of the total. The contribution of polyunsaturated acids (C18:2 and C18:3) was $62.58 \%$.

\subsection{Microscopic observations}

Fig. 1 displays the SEM images of freeze-dried and spray-dried emulsions. Freeze-dried samples appeared as isolated particles not uniformly distributed (Fig. 1AI). On the contrary, spray-dried ones occurred as greater amounts of smaller and regularly dispersed particles (Fig. 1BI). Confocal laser microscopy enabled the observation of microorganisms stained with TO-PRO-3 (Fig. 1AII and BII, left panels). Nile red stain enabled the observation of the capsules (Fig. 1AII and BII, middle panels). The overlap of both images allowed the observation of both capsules (green) and microorganisms (red) (Fig. 1AII and BII, right panels). The dimensions of the spray-dried capsules containing microorganisms were comparable to those of other microorganisms encapsulated using other emulsions (1000-2000 nm for microorganisms and $5000 \mathrm{~nm}$ for emulsions), such as skim milk or acacia gum (Zhang et al., 2015), which may be important at a technological level for their incorporation in food products.

\subsection{Characterization of the emulsions}

The moisture content of freeze-dried and spray-dried samples was within 1.50 and $2.60 \mathrm{~g} / 100 \mathrm{~g}$ ds, and emulsions not containing microorganisms (controls) showed significantly lower values $(0.50-1.00 \mathrm{~g} /$ $100 \mathrm{~g} \mathrm{ds}$ ) (Table 2). In turn, $\mathrm{a}_{\mathrm{w}}$ was significantly lower for freeze-dried samples than for spray-dried ones and no differences for the different $\mathrm{O} / \mathrm{W}$ ratios were observed (Table 2 ).

Fig. 2 shows the $Z$-size and $\zeta$-potential of $\mathrm{O} / \mathrm{W}$ emulsions before and after freeze-drying and spray-drying. Fresh emulsions showed the lowest $Z$-sizes and no significant differences related with the $\mathrm{O} / \mathrm{W}$ ratios were observed (Fig. 2A). The Z-size of spray-dried samples increased up to 1.7 times with regard to that of fresh emulsions, with no significant differences related with the $\mathrm{O} / \mathrm{W}$ ratios (Fig. 2A). For spray-dried samples the obtained $Ð$ was lower than 0.300 , indicating the homogeneity of the population (Table S1). On the contrary, freeze-dried samples were those showing the largest $Z$-sizes (Fig. 2A) and the greatest $Ð$ (above 0.550 , Table S1), indicating a greater heterogeneity. In this case, the 1:2 O/W freeze-dried emulsions were the largest ones and most heterogeneous, followed by $1: 3 \mathrm{O} / \mathrm{W}$ and $1: 4 \mathrm{O} / \mathrm{W}$, thus demonstrating that the higher the oil content, the larger the $Z$-size and the greater the heterogeneity (Fig. 2A and Table S1).

When intended to encapsulate bioactive compounds for food applications, the size of the beads is critical and may determine their applications. For example, large particles can provide sandy textures, affecting the sensory properties of the products and thus, limiting their application in food products (Walstra, Wouters, \& Geurts, 2005). Therefore, $Z$-sizes must be as low as possible. In this work, the Z-sizes of dehydrated emulsions were higher than those of the fresh ones (Fig. 2). This can be explained considering that some aggregation can occur 

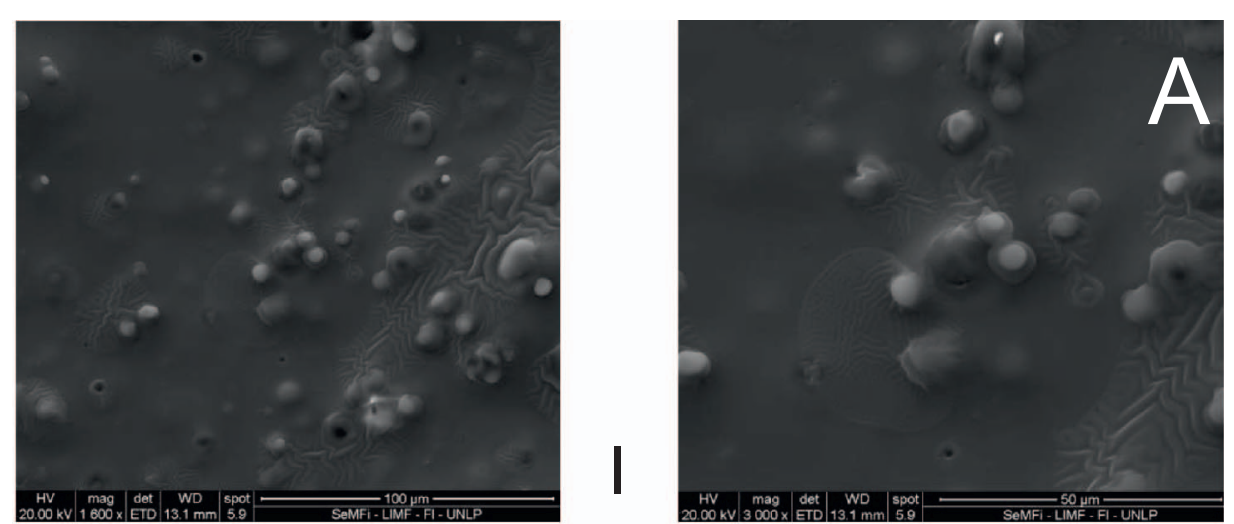

Fig. 1. SEM and confocal laser scanning micrographs of dehydrated emulsions containing microorganisms $(\mathrm{O} /$ W: 1:4). A: freeze-drying; B: spray-drying.

I: SEM images; II: Confocal scanning micrographs: Left panel: red fluorescence showing TO-PRO-3 -labeled $L$. plantarum CIDCA 83114, middle panel: green fluorescence showing Nile red labeling oil; right panel: merged micrographs showing both stains. (For interpretation of the references to colour in this figure legend, the reader is referred to the web version of this article.)
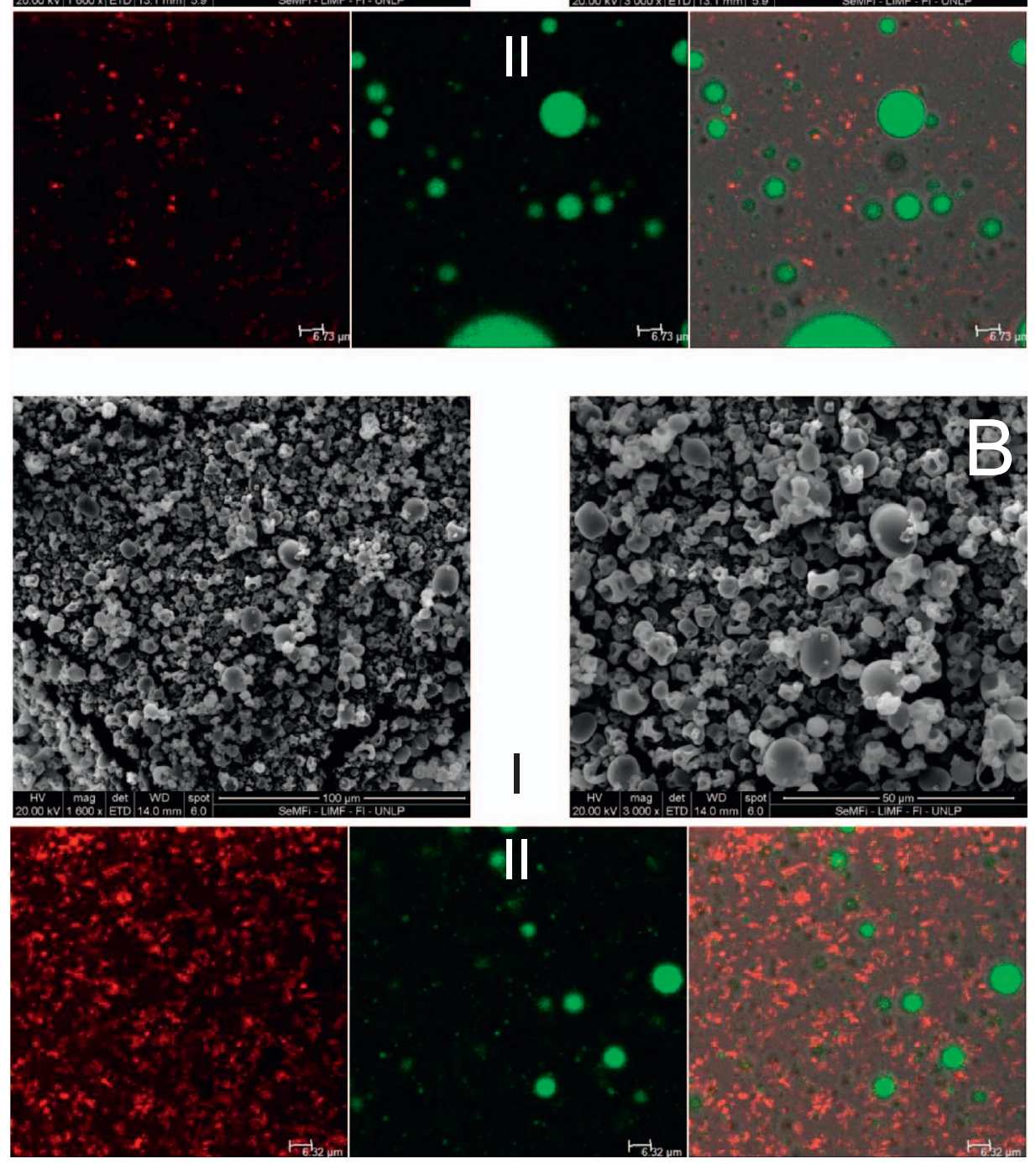

upon dehydration. In addition, the type of dehydration process strongly determined the stability of the obtained beads in terms of $Z$-size and $Ð$ (Fig. 2 and Table S1). Hence, spray-dried emulsions had lower Z-sizes and $Ð$ values than freeze-dried ones. The SEM and confocal images were consistent with these results, showing a homogeneous distribution of spray-dried particles, which was not observed among freeze-dried beads (Fig. 1). The nature of the spray-drying process explains the lower Z-sizes and $Đ$ of the spray-dried emulsions in comparison with the freeze-dried ones. Drying in contact with a hot drying medium enables the obtaining of small droplets and size distributions during the atomization step (Sander \& Penovic, 2014). Moreover, the smaller Z-sizes of spray-dried emulsions lead to greater surface contact, which in turn, can better interact with water. This explains the higher $\mathrm{a}_{\mathrm{w}}$ of spraydried emulsions in comparison with the freeze-dried ones (Table 2).

Regarding the $\zeta$-potential, no significant differences arising from the processes (freeze-drying or spray-drying) were observed (Fig. 2B). However, some differences arising from the $\mathrm{O} / \mathrm{W}$ ratios were detected (Fig. 2). 1:2 O/W were those with the most negative values, followed by $1: 3$ and $1: 4 \mathrm{O} / \mathrm{W}$. In this latter case, $\zeta$-potentials of the freeze-dried emulsions were within -34 and $-36 \mathrm{mV}$. These results indicated that the higher the oil content, the more negative the superficial charge (Fig. 2B). In addition, controls without microorganisms, prepared with $1: 4 \mathrm{O} / \mathrm{W}$ were significantly more negative than their counterparts containing bacteria. 
Table 2

Moisture and water activity of the freeze-dried and spray-dried emulsions.

\begin{tabular}{lll}
\hline Samples & Moisture $(\mathrm{g} / 100 \mathrm{~g} \mathrm{ds})$ & $\mathrm{a}_{\mathrm{w}}$ \\
\hline Freeze-drying & & \\
O/W 1:2 & $1.51 \pm 0.10^{\mathrm{a}}$ & $0.13 \pm 0.04^{\mathrm{A}}$ \\
O/W 1:3 & $1.60 \pm 0.13^{\mathrm{a}}$ & $0.14 \pm 0.03^{\mathrm{A}}$ \\
O/W 1:4 & $2.26 \pm 0.09^{\mathrm{a}}$ & $0.17 \pm 0.05^{\mathrm{A}}$ \\
O/W 1:4 (control) & $0.50 \pm 0.02^{\mathrm{b}}$ & $0.24 \pm 0.07^{\mathrm{B}}$ \\
Spray-drying & & \\
O/W 1:2 & $1.90 \pm 0.10^{\mathrm{a}^{\prime}}$ & $0.30 \pm 0.05^{\mathrm{A}^{\prime}}$ \\
O/W 1:3 & $2.59 \pm 0.19^{\mathrm{a}^{\prime}}$ & $0.32 \pm 0.05^{\mathrm{A}^{\prime}}$ \\
O/W 1:4 & $2.14 \pm 0.15^{\mathrm{a}^{\prime}}$ & $0.32 \pm 0.05^{\mathrm{A}^{\prime}}$ \\
O/W 1:4 (control) & $0.96 \pm 0.09^{\mathrm{b}^{\prime}}$ & $0.27 \pm 0.01^{\mathrm{A}^{\prime}}$
\end{tabular}

Different letters indicate significant differences $(p<0.05)$.

\section{Freeze-dried}
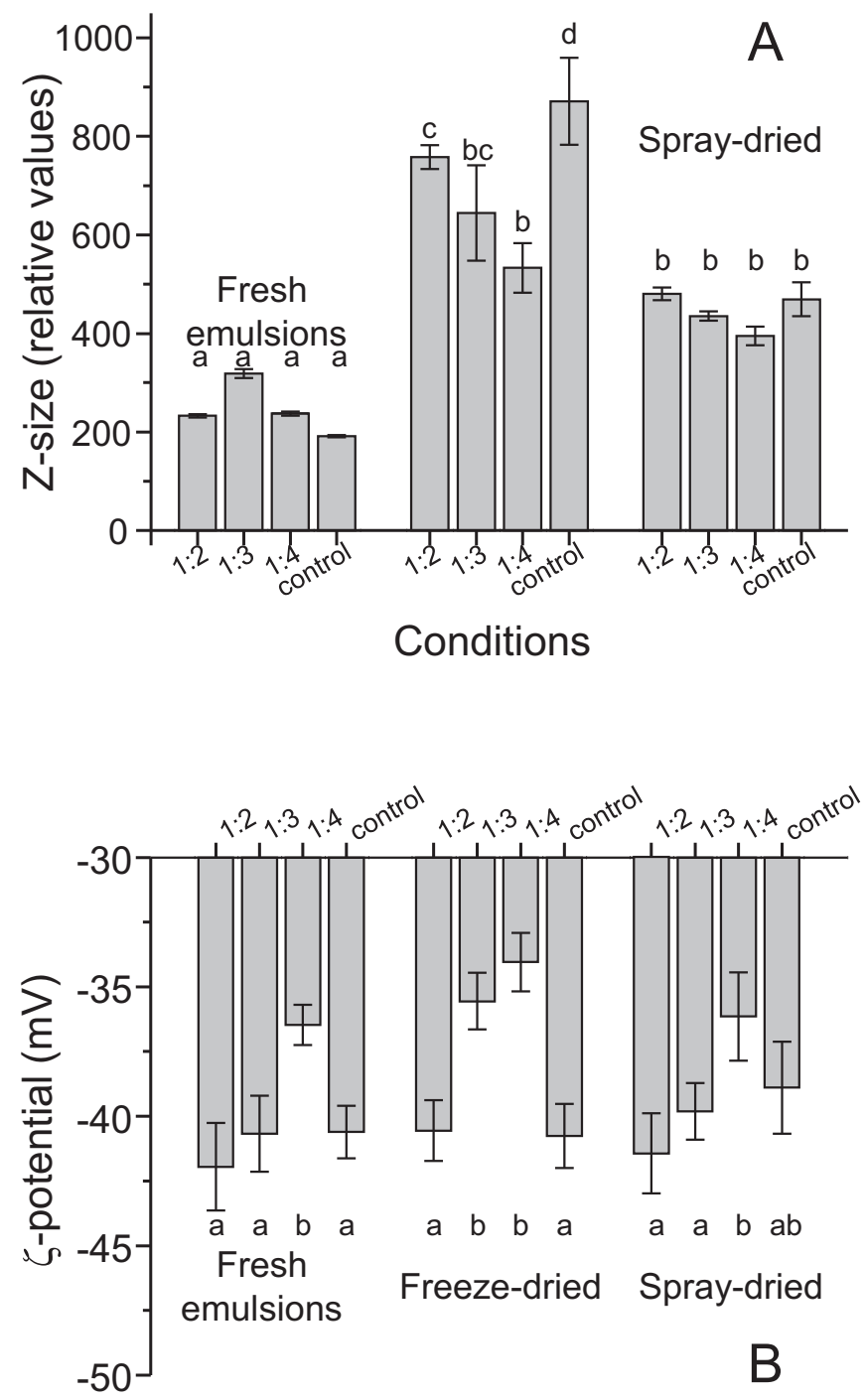

Fig. 2. Particle size ( $Z$-average) (A) and $\zeta$-potential (B) of freshly obtained $\mathrm{O} / \mathrm{W}$ emulsions and freeze-dried and spray-dried ones. Controls refer to dehydrated emulsions not containing microorganisms (O/W ratio: 1:4). Different letters indicate significant differences $(p<0.05)$.

\subsection{Stability of the emulsions}

Fig. 3 shows the stability of freeze-dried and spray-dried emulsions as determined by the induction time and the peroxide values. Freeze-
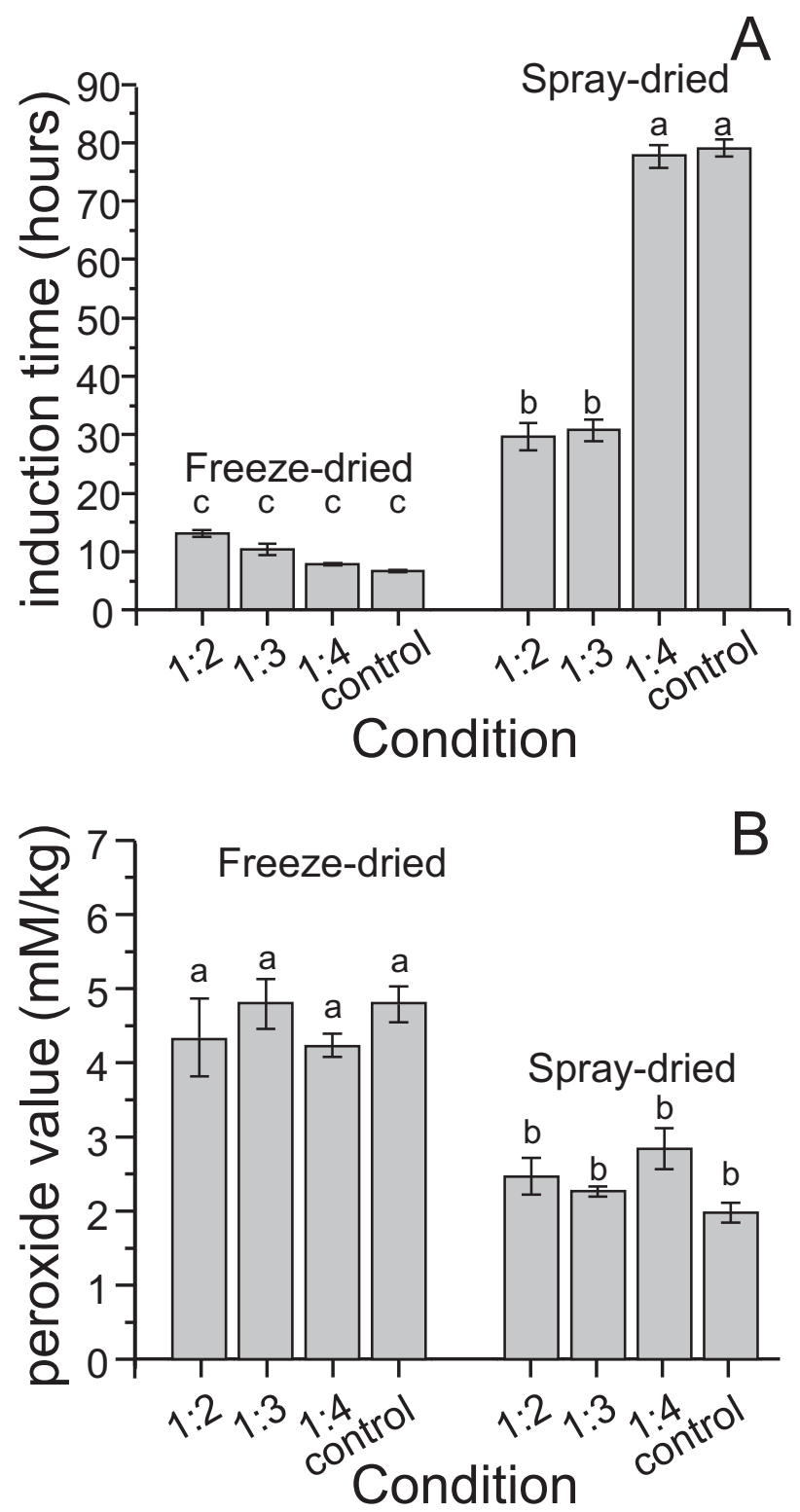

Fig. 3. A. Induction times of freeze-dried and spray-dried emulsions. Controls refer to dehydrated emulsions not containing microorganisms (O/W ratio: 1:4). Different letters indicate significant differences $(p<0.05)$.

B. Peroxide values $(\mathrm{mM})$ of freeze-dried and spray-dried emulsions. Controls refer to dehydrated emulsions not containing microorganisms (O/W ratio: 1:4). Different letters indicate significant differences $(p<0.05)$.

dried samples had induction times within 6 and $13 \mathrm{~h}$, with no significant differences related with the $\mathrm{O} / \mathrm{W}$ ratios (Fig. 3A). On the contrary, spray-dried ones showed much larger induction times. They were about $30 \mathrm{~h}$ for $1: 2$ and $1: 3 \mathrm{O} / \mathrm{W}$, and about 80 , for $1: 4 \mathrm{O} / \mathrm{W}$ and for the control (also prepared with the same $\mathrm{O} / \mathrm{W}$ ratio). In regard to peroxidation, spray-dried samples showed significantly lower peroxide values than freeze-dried samples $(p<0.05)$ (Fig. 3B), which reinforce their higher stability.

The fatty acid composition of okara oil could explain its stability in the desiccated emulsions (Fig. 3, Table 1). In fact, canola and sesame oils, as well as milk fats have been used to encapsulate different species of lactic acid bacteria (Hou et al., 2003; Pimentel-González et al., 2009; Rodríguez-Huezo et al., 2014; Zhang et al., 2015), but they often require double emulsification strategies and/or deposition of additional aqueous phases to correctly shell the obtained beads, and thus protect 
microorganisms. Canola oil has $57 \%$ of monounsaturated and $21 \%$ of polyunsaturated fatty acids (Matthaus, Özcan, \& Al Juhaimi, 2016). In turn, sesame oil includes $39 \%$ of monounsaturated, $46 \%$ of polyunsaturated, and $13 \%$ of saturated fatty acids (Nzikou et al., 2009). It must also be considered that milk fat includes higher amounts of shorter fatty acids and lower amounts of mono and polyunsaturated ones (Månsson, 2008). In contrast, okara oil had a high contribution of polyunsaturated fatty acids, in particular, C18:2 (Table 1). In addition, the total content of polyunsaturated fatty acids $(18: 2+18: 3)$ reached $62.58 \%$, and that of C18:1, 21.34\% (Table 1). The presence of higher amounts of polyunsaturated fatty acids would explain the stability of okara oil emulsions (Fig. 3). As the droplets in an $\mathrm{O} / \mathrm{W}$ emulsion are usually liquid because both the oil and water phases must be in a fluid state when emulsions are prepared (temperature $\sim 20^{\circ} \mathrm{C}$ ), polyunsaturated fatty acids (with lower melting temperatures), appear as more adequate ones to form more stable emulsions, avoiding crystallization processes (Bai \& McClements, 2016).

In spite of these advantages, the presence of high concentrations of polyunsaturated fatty acids could make emulsions more susceptible to oxidation. The induction times and peroxide values of dehydrated emulsions (in particular those obtained by spray-drying 1:4 O/W emulsions) were much higher and lower, respectively (Fig. 3), than those of other edible oils (Bae \& Lee, 2008; Binsi et al., 2017; Ixtaina, Julio, Wagner, Nolasco, \& Tomás, 2015; Pereyra Boué, Costamagna, Rodríguez, Speltini, \& Coppo, 2009). This behavior can be explained considering the presence of antioxidant polyphenolic compounds (genistein, daidzein) in okara oil (Quitain et al., 2006).

Two comparisons could explain the high induction times for spraydried 1:4 O/W emulsions: $a$-comparing the dehydration process (freezedrying vs spray-drying), and $b$-comparing the $\mathrm{O} / \mathrm{W}$ ratios.

If consider that freeze-dried samples were larger and less homogeneous than spray-dried ones (Table S1 and Fig. 1), they expose a larger surface to the air, thus being more prompt to oxidation. In this regard, Miyagawa and Adachi (2017) showed demonstrated that a reduction of the oil droplet size suppresses or retards autoxidation. Microencapsulated lipids or oils exhibit distinct features in the oxidation process. In addition, a reduction in the oil droplet size is also effective for suppressing or retarding the oxidation of microencapsulated oils.

Regarding the $\mathrm{O} / \mathrm{W}$ ratios, spray-dried emulsions containing 1:4 O/ $\mathrm{W}$ ratios (samples containing bacteria and controls) had much higher induction times. This observation can be explained considering that higher amounts of proteins better stabilize $\mathrm{O} / \mathrm{W}$ emulsions. This observation has already been reported for other emulsions (Bai \& McClements, 2016; Evans, Ratcliffe, \& Williams, 2013; Miyagawa \& Adachi, 2017).

\subsection{Stability of the encapsulated microorganisms}

Fig. 4 shows the culturability of L. plantarum CIDCA 83114 after freeze-drying and spray-drying. No significant decrease of culturability was observed after spray-drying, regardless the $\mathrm{O} / \mathrm{W}$ ratio. On the contrary, freeze-drying was less efficient, leading to significant decreases of culturability $(p<0.05)$. In addition, the culturability within this group showed to be dependent on the $\mathrm{O} / \mathrm{W}$ ratio. In fact, using 1:2 $\mathrm{O} / \mathrm{W}$ was the worst condition, as culturability decreased from $13.91 \pm 0.73 \log \mathrm{CFU} / \mathrm{g}$ to $9.40 \pm 0.31 \log \mathrm{CFU} / \mathrm{g} .1: 4 \mathrm{O} / \mathrm{W}$ resulted a better condition, as a drop of $1.53 \pm 0.08 \mathrm{log} \mathrm{CFU} / \mathrm{g}$ was observed (Fig. 4). This indicates that the higher the oil content in the emulsion, the lower the bacteria culturability. Although bacterial culturability was above those required for probiotic products [Aquilina et al., 2013; Hill et al., 2014; Tripathi \& Giri, 2014], the physical properties of the freeze-dried capsules (especially high $Ð$ indexes and $Z$-sizes) make them unappropriated to encapsulate microorganisms. On the contrary, spraydried emulsions looked as more homogenous (lower $Đ$ values) and nonsticky powders with lower Z-sizes, larger induction times and lower peroxide values (Figs. 2, 3; Tables 2, S1). Thanks to these properties no

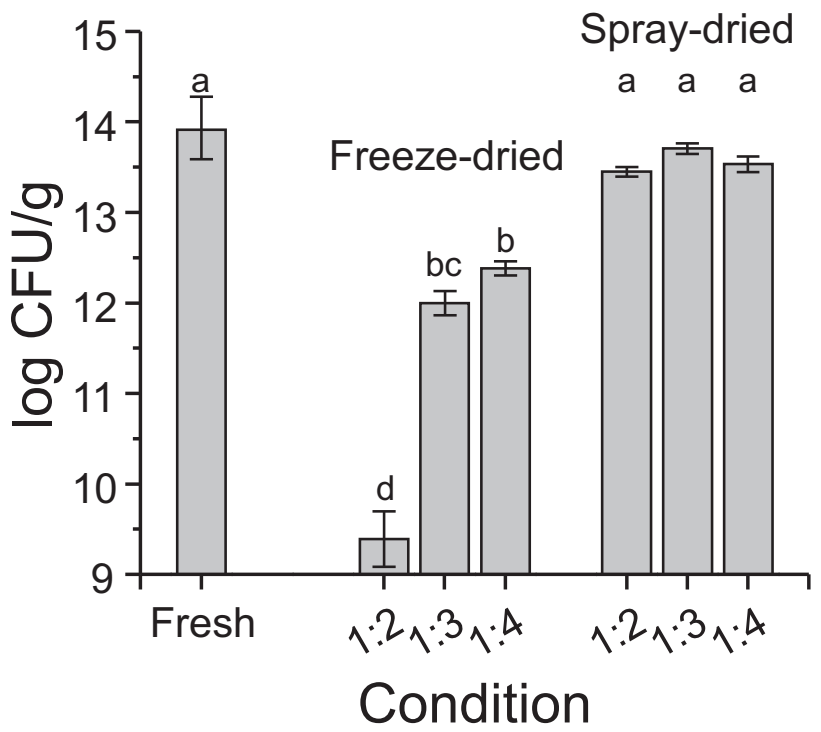

Fig. 4. Log CFU/g of fresh cultures and after freeze-drying and spray-drying in emulsions prepared with different $\mathrm{O} / \mathrm{W}$ ratios $(1: 2 ; 1: 3 ; 1: 4)$. Different letters indicate significant differences $(p<0.05)$. Plate counts for non-emulsified freeze-dried and spray-dried bacteria were $8.09 \pm 0.54 \log \mathrm{CFU} / \mathrm{mL}$ and $8.52 \pm 0.46 \log \mathrm{CFU} / \mathrm{mL}$, respectively.
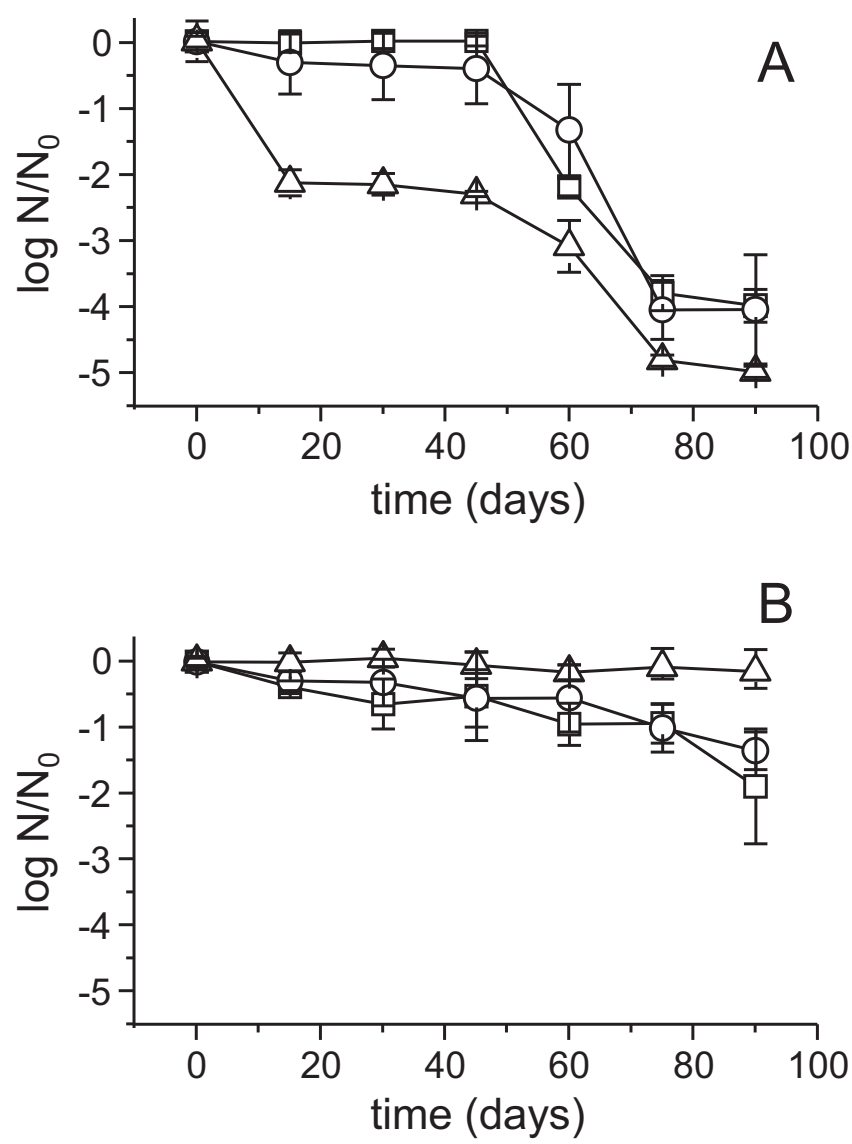

Fig. 5. Log $\mathrm{N} / \mathrm{N}_{0}$ of L. plantarum CIDCA 83114 during storage at $4{ }^{\circ} \mathrm{C} . \mathrm{N}_{0}: \log \mathrm{CFU} / \mathrm{g}$ immediately after A. freeze-drying or B. spray-drying (time 0 ). The values of $\mathrm{N}_{0}$ correspond to the CFU/g shown in Fig. 4; N: $\log \mathrm{CFU} / \mathrm{g}$ at each time of storage. Different symbols indicate different $\mathrm{O} / \mathrm{W}$ ratios. Squares: 1:4; circles: 1:3; triangles: 1:2. A: freezedrying; B: spray-drying. 
significant decrease of culturability neither during the process nor during storage (Figs. 4, 5), was observed, thus making this system more appropriate to encapsulate $L$. plantarum CIDCA 83114.

Storage also showed a differential behavior for freeze-dried and spray-dried microorganisms (Fig. 5). 1:3 and 1:4 O/W showed a similar behavior for freeze-dried samples, with no significant decrease of culturability up to day 45 (Fig. 5A). The drop of culturability started at day 60 , and after 90 days of storage, it decreased about $4 \log$ for both $\mathrm{O} / \mathrm{W}$ emulsions. The culturability of bacteria freeze-dried in 1:2 O/W emulsions started decreasing already at day 15, and dropped $5.00 \pm 0.09$ after 90 days of storage (Fig. 5A). On the contrary, spray-dried emulsions were much better encapsulation systems also during storage, as no significant decrease of culturability was observed up to day 60 in none of the conditions assayed (Fig. 5B). Furthermore, the drop of culturability observed after 90 days of storage was not $>1.89 \pm 0.87$ in none of the cases. If considering that spray-drying is a cost effective technique, easily scalable and with low energetic consumption, the higher culturability of spray-dried microorganisms [consistent with the higher physical-chemical stability of spray-dried emulsions (Fig. 3)] appears as a very promising result.

As a whole, the results obtained in this work clearly showed that a greater physical-chemical stability leads to a greater stability for the encapsulated microorganisms, thus demonstrating the importance of defining adequate formulations for the emulsions aiming at efficiently encapsulate microorganisms.

\section{Conclusion}

Okara components are nutritionally valuable ingredients for food and/or pharmaceutical industries. Therefore, attempts to incorporate them in the formulation of functional foods is matter of increasing research work. One of the main achievements of this work was to use okara oil in the formulation of stable emulsions. The obtained results demonstrated that the adequate formulation of emulsions results in adequate materials to safely entrap lactobacilli.

Taking into account that okara oil is a by-product and spray-drying is a cost-effective and easily scalable process, with low energetic consumption, the production of spray-dried emulsions entrapping $L$. plantarum CIDCA 83114 appears as an adequate alternative for the production of starters at a large scale. Moreover, the composition of okara oil, including polyunsaturated fatty acids and antioxidants, provides an additional source of high quality nutrients as vehicles of potentially probiotic microorganisms, whose importance in human health is out of question. Taking this into account, the results support the use of okara oils as suitable ingredients to formulate stable emulsions, with promising applications in the development of novel functional foods.

Supplementary data to this article can be found online at https:// doi.org/10.1016/j.foodres.2017.12.053.

\section{Acknowledgments}

This work was supported by the Argentinean Agency for the Scientific and Technological Promotion (ANPCyT) (Project PICT/2014/ 0912). E.G., and A.G.-Z. are members of the research career CONICET. G.Q. is doctoral fellow from CONICET.

\section{Competing interests}

The authors declare that they have no competing interests.

\section{Author's contributions}

G.Q. did the experimental work. E.G. conceived the experimental design and participated in the experimental work. A.G.-Z analyzed results, coordinated discussions and wrote the manuscript. All authors approved the final version of the manuscript.

\section{References}

Aquilina, G., Bach, A., Bampidis, V., Bastos, M. L., Flachowsky, G., Gralak, M. A., Westendorf, J. (2013). Scientific opinion on the safety and efficacy of probiotic LACTINA ${ }^{\oplus}$ (Lactobacillus acidophilus, Lactobacillus helveticus, Lactobacillus bulgaricus, Lactobacillus lactis, Streptococcus thermophilus and Enterococcus faecium) for chickens for fattening and piglets. EFSA Journal, 11, 3170-3183.

Association of Official Analytical Chemists (AOAC) (1980). Official methods of analysis (13th ed). Washington, DC, USA: AOAC International.

Association of Official Analytical Chemists (AOAC) (1995). Washington, DC, USA (16th ed).

Bae, E. K., \& Lee, S. J. (2008). Microencapsulation of avocado oil by spray drying using whey protein and maltodextrin. Journal of Microencapsulation, 25, 549-560.

Bai, L., \& McClements, D. J. (2016). Extending emulsion functionality: Post-homogenization modification of droplet properties. PRO, 4, 17-35.

Binsi, P. K., Nayak, N., Sarkar, P. C., Jeyakumari, A., Ashraf, P. M., Ninan, G., \& Ravishankar, C. N. (2017). Structural and oxidative stabilization of spray dried fish oil microencapsulates with gum arabic and sage polyphenols: Characterization and release kinetics. Food Chemistry, 219, 158-168.

Borhan, F. P., Gani, S. S. A., \& Shamsuddin, R. (2014). The use of D-optimal mixture design in optimising okara soap formulation for stratum corneum application. The Scientific World Journal173979 (8 pages https://www.hindawi.com/journals/tswj/ 2014/173979/).

Chávarri, M., Marañón, I., \& Villarán, M. C. (2012) Encapsulation technology to protect probiotic bacteria. In Probiotics. Chapter 23. Eds. E.C. Rigobelo. ISBN: 978-953-510776-7, 654 pages, InTech.

Dianawati, D., Mishra, V., \& Shah, N. P. (2016). Viability, acid and bile tolerance of spray dried probiotic bacteria and some commercial probiotic supplement products kept at room temperature. Journal of Food Science, 81, M1472-1479.

Evans, M., Ratcliffe, I., \& Williams, P. A. (2013). Emulsion stabilisation using polysaccharide-protein complexes. Current Opinion in Colloid \& Interface Science, 18 $272-282$.

FAO (2010). Fats and fatty acids in human nutrition report of an expert consultation. FAO Food and Nutrition Paper. 91Rome: FAO (Final report).

Garrote, G. L., Abraham, A. G., \& De Antoni, G. L. (2001). Chemical and microbiological characterisation of kefir grains. Journal of Dairy Research, 68, 639-652.

Golowczyc, M. A., Gugliada, M. J., Hollmann, A., Delfederico, L., Garrote, G. L., Abraham, A. G., ... De Antoni, G. (2008). Characterization of homofermentative lactobacilli isolated from kefir grains: Potential use as probiotic. Journal of Dairy Research, 75, 211-217.

Golowczyc, M. A., Silva, J., Teixeira, P., De Antoni, G. L., \& Abraham, A. G. (2011) Cellular injuries of spray-dried Lactobacillus spp. isolated from kefir and their impact on probiotic properties. International Journal of Food Microbiology, 144, 556-560.

Hill, C., Guarner, F., Reid, G., Gibson, G. R., Merenstein, D. J., Pot, B., ... Sanders, M. E. (2014). Expert consensus document: The International Scientific Association for Probiotics and Prebiotics consensus statement on the scope and appropriate use of the term probiotic. Nature Reviews Gastroenterology \& Hepatology, 11, 506-514.

Hou, R. C. W., Lin, M. Y., Wang, M. M., \& Tzen, J. T. (2003). Increase of viability of entrapped cells of Lactobacillus delbrueckii ssp. bulgaricus in artificial sesame oil emulsion. Journal of Dairy Science, 86, 424-428.

Hugo, A. A., Kakisu, E., De Antoni, G. L., \& Pérez, P. F. (2008). Lactobacilli antagonize biological effects of enterohaemorrhagic Escherichia coli in vitro. Letters in Applied Microbiology, 46, 613-619.

IUPAC (1992). Standard methods for the analysis of oils, fats and derivates. In P.C.H.A (Ed.). International Union of Pure and Applied Chemistry. England, Oxford: Oxford, Blackwell Scientific Publications Inc.

Ixtaina, V. Y., Julio, L. M., Wagner, J. R., Nolasco, S. M., \& Tomás, M. C. (2015). Physicochemical characterization and stability of chia oil microencapsulated with sodium caseinate and lactose by spray-drying. Powder Technology, 271, 26-34.

Jacobsen, C. (2010). Understanding and reducing oxidative flavour deterioration in foods. In E. A. Decker, R. Elias, \& D. J. McClements (Eds.). Woodhead Publishing Series in Food Science, Technology and Nutrition. (pp. 122-142). Cambridge, UK: Woodhead Publishing.

Kakisu, E., Abraham, A. G., Tironi Farinati, C., Ibarra, C., \& De Antoni, G. L. (2013). Lactobacillus plantarum isolated from kefir protects vero cells from cytotoxicity by type-II Shiga toxin from Escherichia coli O157:H7. Journal of Dairy Research, 80, 64-71.

Kakisu, E., Bolla, P., Abraham, A. G., de Urraza, P., \& De Antoni, G. L. (2013). Lactobacillus plantarum isolated from kefir: Protection of cultured Hep-2 cells against Shigella invasion. International Dairy Journal, 33, 22-26.

Li, Y., Hao, J., Cheng, Y., Zhao, R., Yin, L., \& Li, L. (2012). Improvement of okara mouthfeel by Aspergillus niger and Aspergillus oryzae fermentation. Nongye Gongcheng Xuebao/Trans Chinese Society of Agricultural Engineering, 28, 248-253.

de Man, J. O., Rogosa, M., \& Sharpe, M. E. (1960). A medium for the cultivation of lactobacilli. Journal of Applied Bacteriology, 23, 130-135.

Månsson, H. L. (2008). Fatty acids in bovine milk fat. Food \& Nutrition Research, 52, 1-3.

Matthaus, B., Özcan, M. M., \& Al Juhaimi, F. (2016). Some rape/canola seed oils: Fatty acid composition and tocopherols. Zeitschrift für Naturforschung. Section C, 71, 73-77.

McClements, D. J. (1999). Food emulsions: Principles, practice and techniques. Florida: CRC Press.

Miyagawa, Y., \& Adachi, S. (2017). Dispersion and oxidative stability of O/W emulsions and oxidation of microencapsulated oil. Bioscience, Biotechnology, and Biochemistry, $81,625-633$.

Nzikou, J. M., Matos, L., Bouanga-Kalou, G., Ndangui, C. B., Pambou-Tobi, N. P. G., Kimbouguila, A., ... Desobry, S. (2009). Chemical composition of the seeds and oil of 
sesame (Sesamum indicum L.) grown in Congo-Brazzaville. Advance Journal of Food Science and Technology, 1, 6-11.

Partanen, R., Hakala, P., Sjövall, O., Kallio, H., \& Forssell, P. (2005). Effect of relative humidity on the oxidative stability of microencapsulated sea buckthorn seed oil. Journal of Food Science, 70, E37-E43.

Pereyra Boué, M. M., Costamagna, D., Rodríguez, P., Speltini, C., \& Coppo, G. (2009). Auto-oxidation of commercial vegetable oils. Rumbos Technologicos, 1, 53-63.

Petrovic, T., Nedovic, V., Dimitrijevic-Brankovic, S., Bugarski, B., \& Lacroix, C. (2007). Protection of probiotic microorganism by microencapsulation. Chemical Industry and Chemical Engineering Quarterly, 13, 169-174.

Pimentel-González, D. J., Campos-Montiel, R. G., Lobato-Calleros, C., Pedroza-Islas, R., \& Vernon-Carter, E. J. (2009). Encapsulation of Lactobacillus rhamnosus in double emulsions formulated with sweet whey as emulsifier and survival in simulated gastrointestinal conditions. Food Research International, 42, 292-297.

Quintana, G., Gerbino, E., \& Gomez-Zavaglia, A. (2017). Okara: A nutritionally valuable by-product able to stabilize Lactobacillus plantarum during freeze-drying, spraydrying, and storage. Frontiers in Microbiology, 8, 641-650.

Quitain, A. T., Oro, K., Shunsaku, K., \& Moriyoshi, T. (2006). Recovery of oil components of okara by ethanol-modified supercritical carbon dioxide extraction. Bioresource Technology, 97, 1509-1514.

Rodríguez-Huezo, M. E., Estrada-Fernandez, A. G., García-Almendarez, B. E., LudenaUrquizo, F., Campos-Montiel, R. G., \& Pimentel-Gonzalez, D. J. (2014). Viability of Lactobacillus plantarum entrapped in double emulsion during Oaxaca cheese manufacture, melting and simulated intestinal conditions. Food Science and Technology, 59,
$768-773$.

Sander, A., \& Penovic, T. (2014). Droplet size distribution obtained by atomization with two-fluid nozzles in a spray-dryer. Chemical Engineering and Technology, 37, 1-13.

Santos, M., Gerbino, E., Araujo-Andrade, C., Tymczyszyn, E. E., \& Gomez-Zavaglia, A. (2014). Stability of freeze-dried Lactobacillus delbrueckii subsp. bulgaricus in the presence of galacto-oligosaccharides and lactulose as determined by near infrared spectroscopy. Food Research International, 59, 53-60.

Shurtleff, W., \& Aoyagi, A. (2000). Tofu \& soymilk production: A craft and technical manual. Lafayette, CA. (USA): Soyfoods Center.

Stanojevic, S. P., Barac, M. B., Pesic, M. B., Jankovic, V. S., \& Vucelic-Radovic, B. V. (2013). Bioactive proteins and energy value of okara as a byproduct in hydrothermal processing of soy milk. Journal of Agricultural and Food Chemistry, 61, 9210-9219.

Tripathi, M. K., \& Giri, S. K. (2014). Probiotic functional foods: Survival of probiotics during processing and storage. Journal of Functional Foods, 9, 225-241.

Tymczyszyn, E. E., Díaz, M. R., Pataro, A., Sandonato, N., Gómez-Zavaglia, A., \& Disalvo, E. A. (2008). Critical water activity for the preservation of Lactobacillus bulgaricus by vacuum drying. International Journal of Food Microbiology, 128, 342-347.

Vong, W. C., \& Liu, S. Q. (2016). Biovalorisation of okara (soybean residue) for food and nutrition. Trends in Food Science and Technology, 52, 139-147.

Walstra, P., Wouters, J. T. M., \& Geurts, T. J. (2005). Dairy science and technology (2nd Edition). Boca Raton (USA): CRC Taylor and Francis.

Zhang, Y., Lin, J., \& Zhong, O. (2015). The increased viability of probiotic Lactobacillus salivarius NRRL B-30514 encapsulated in emulsions with multiple lipid-protein-pectin layers. Food Research International, 71, 9-15. 